\title{
ЭЛЕКТРОМИОГРАФИЧЕСКИЕ ПОКАЗАТЕЛИ У ПАЦИЕНТОВ С ДЕФИЦИТОМ МЕСТА В ЗУБНОМ РЯДУ
}

\section{ELECTROMYOGRAPHIC PARAMETERS IN PATIENTS WITH A LACK OF SPACE IN THE DENTITION}

\author{
A. Klimov \\ M. Rozhkova \\ A. Lepilin \\ A. Kondratyuk \\ S. Fishchev \\ I. Orlova
}

Summary. Introduction. Electromyography (EMG) of the masticatory muscles allows us to determine the degree of adaptation of patients to the new conditions of the masticatory-speech apparatus in the process of orthodontic and orthopedic treatment of patients with a lack of space in the dentition [4].

Goal. To study electromyographic parameters of the masticatory muscles proper in patients with crowding of teeth in the anterior part. Materials and methods. 42 patients aged 21-35 years were examined (26 women, 16 men) with crowding of teeth in the anterior part of the upper and lower jaws, which were treated with removable and non-removable orthodontic devices, the quality of treatment was assessed by changing the EMG indicators of plaster models and a computer tomogram. The comparison group consisted of 45 people aged 21-35 years (25 women, 20 men) with intact dentition and physiological types of bite. Results. EMG indicators of all groups of patients before treatment were lower than those obtained in the comparison group. Conclusions: EMG indicators of all groups of patients before treatment were lower than those obtained in the comparison group, and after treatment, the indicators approached the values of the comparison group.

Keywords: crowding of teeth, plaster models, dentition, orthodontic treatment.
Климов Андрей Геннадьевич

К.м.н., доцент, Санкт-Петербургский государственный педиатрический медицинский университет Министерства здравоохранения РФ pstom4@zdrav.spb.ru

Рожкова Мария Геннадьевна

Ассистент, Санкт-Петербургский государственный педиатрический медицинский университет

Министерства здравоохранения РФ

rozmaria2010@yandex.ru

Лепилин Александр Викторович

Д.м.н., профессор, Саратовский государственный медицинский университет имени В. И. Разумовского

Министерства здравоохранения РФ lepilins@mail.ru

Кондратюк Андрей Александрович

Ассистент, Санкт-Петербургский государственный педиатрический медицинский университет

Министерства здравоохранения РФ

kondratyuk.andrey@icloud.com

Фищев Сергей Борисович

Д.м.н., профессор, Санкт-Петербургский государственный педиатрический медицинский университет Министерства здравоохранения РФ

super.kant@yandex.ru

Орлова Ирина Викторовна

К.м.н., дочент Санкт-Петербургский государственный педиатрический медицинский университет Министерства здравоохранения РФ

orisha@mail.ru

Аннотация. Введение. Электромиография (ЭМГ) жевательных мышц позволяет определить степень адаптации пациентов к новым условиям жевательно-речевого аппарата в процессе ортодонтического и ортопедического лечения пациентов с дефицитом места в зубном ряду [4].

Цель. Изучить электромиографические показатели собственно жевательных мышц у пациентов со скученностью зубов в переднем отделе.

Материалы и методы. Обследовано 42 пациента в возрасте от 21-35 лет (женщин 26 человек, мужчин 16 человек) со скученностью зубов в переднем отделе верхней и нижней челюстей, которым проводили лечение съёмными и несъёмными ортодонтическими аппаратами Качество лечения оценивали с помощью изменения показателей ЭМГ гипсовых моделей и компьютерной томограммы. Группой сравнения являлись 45 человек в возрасте 21-35 лет (женщин 25 человек, мужчин 20 человек) с интактными зубными рядами и физиологическими видами прикуса. 


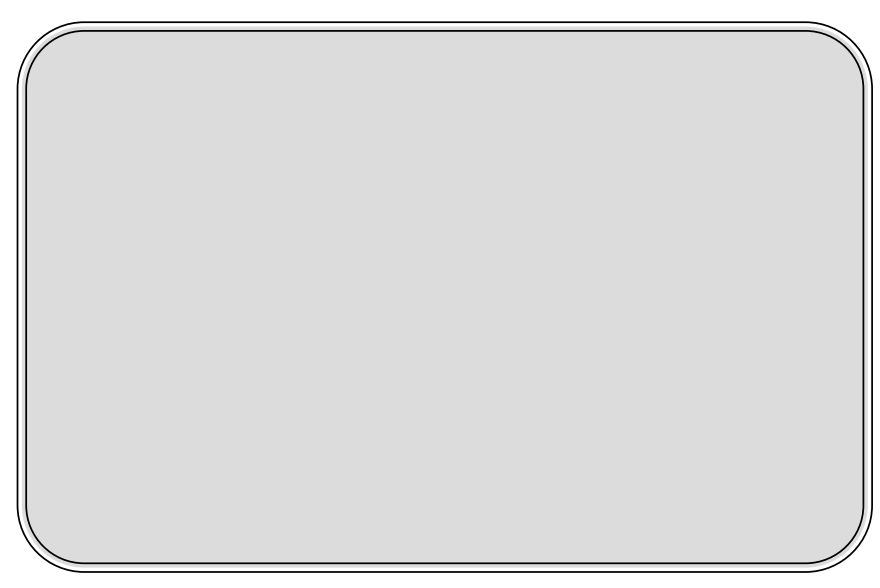

$\Pi$ ри постоянном прикусе у пациентов со скученным положением зубов СПЗ важнейшим диагностическим критерием является оценка наличия места в зубной дуге и выявление потребности в его увеличении. При скученном положении зубов риск возникновения кариеса и заболеваний тканей пародонта, неудовлетворительная гигиена усиливает риск развития стоматологических заболеваний. Скученность зубов это патология зубных рядов, характеризующаяся тесным расположением зубов в результате имеющегося дефицита места - является одним из наиболее распространенных видов аномалий формирования зубных рядов, которая нередко является самостоятельной патологией [3].

Также было предложено определение длины переднего отрезка верхней зубной дуги в зависимости от суммы ширины коронок верхних резцов. При этом измеряется расстояние от срединной точки между центральными резцами с вестибулярной поверхности или режущего края по срединной линии челюсти до ее пересечения с линией, соединяющей точки Pont на первых премолярах [1, 2]. В норме длина переднего отрезка нижней ЗД должна быть на 2 мм меньше значения длины переднего отрезка верхней ЗД [3].

Диагноз СПЗ устанавливается на основании результатов клинических и рентгенологических обследований и при изучении контрольно-диагностических моделей челюсти. В ходе диагностики оценивается ширина зубного ряда в районе премоляров и моляров с использованием метода Пона, а также ширина апикальных базисов по Снагиной. При сравнении данных с индивидуальной нормой определяется выраженность изменений зубного ряда $[5,6]$.

Электромиографические показатели жевательных мышц позволяют оценить степень адаптации пациентов с дефицитом места в зубном ряду в процессе ортодонтического лечения $[2,7]$.
Результаты. ЭМГ показатели всех групп пациентов, до лечения были ниже показателей, полученных у лиц группы сравнения.

Выводы. ЭМГ показатели всех групп пациентов, до лечения были ниже показателей, полученных у лиц группы сравнения, а после лечения показатели приблизились к значениям группы сравнения.

Ключевые слова: скученность зубов, гипсовые модели, зубные ряды, ортодонтическое лечение.

\section{Цель исслеАования}

Изучить электромиографические показатели собственно жевательных мышц у пациентов со скученностью зубов в переднем отделе.

\section{Материалы \\ и мето}

Обследовано 42 пациента в возрасте от 21-35 лет (женщин 26 человек, мужчин 16 человек) со скученностью зубов в переднем отделе верхней и нижней челюстей, которым проводили лечение съёмными и несъёмными ортодонтическими аппаратами (1группа), 36 пациентов в возрасте 21-35 лет (женщин 24 человек, мужчин 12 человек) со скученностью зубов в переднем отделе верхней и нижней челюстей, которым проводили лечение несъёмными ортодонтическими аппаратами и сепарацию центральных резцов верхней и нижней челюстей (2 группа), 28 пациентов в возрасте 21-35 лет (женщин 15 человек, мужчин 13 человек) со скученностью зубов в переднем отделе верхней и нижней челюстей, которым проводили лечение несъёмными ортодонтическими аппаратами в сочетании удалении зубов (3 группа).

Группой сравнения являлись 45 человек в возрасте 21-35 лет (женщин 25 человек, мужчин 20 человек), с интактными зубными рядами и физиологическими видами прикуса. У пациентов 3 группы проводилось комплексное обследование с применением современных методов компьютерной диагностики и моделирования (ортодонтическое и хирургическое лечение). Пациентам 2 группы проводили комплексное обследование и компьютерную диагностику (ортодонтическое лечение с применением сепарации центральных резцов верхней и нижней челюстей). Пациентам 1 группы также проводили комплексное обследование и компьютерную диагностику (ортодонтическое лечение съёмными и несъёмными аппаратами). 
Таблица 1. Амплитудные показатели ЭМГ (мкВ) мышц группы сравнения.

\begin{tabular}{l|l|}
\multirow{2}{*}{$\begin{array}{l}\text { Показатели } \\
\text { ЭМг }\end{array}$} & Результаты показателей ЭМг (мкВ) мышц: \\
\cline { 2 - 2 } & собственно жевательной \\
\hline А н & $372,9 \pm 11,7$ \\
\hline А м & $423,4 \pm 14,8$ \\
\hline
\end{tabular}

Таблица 2. Временные параметры ЭМГ группы сравнения.

\begin{tabular}{|l|l|}
\multirow{2}{*}{$\begin{array}{l}\text { Показатели } \\
\text { ЭМГ }\end{array}$} & Результаты временных показателей ЭмГ (в сек.) мышц: \\
\cline { 2 - 2 } & собственно жевательные \\
\hline БЭА & $0,36 \pm 0,03$ \\
\hline БЭП & $0,41 \pm 0,03$ \\
\hline «К» & $0,90+0,08$ \\
\hline ДЦ & $0,77+0,12$ \\
\hline К-во ДЦ & $18,3+1,7$ \\
\hline ППЖ & $14,2+1,6$ \\
\hline
\end{tabular}

Таблица 3. Временные показатели собственно жевательных мышц пациентов 1группы до лечения в секундах.

\begin{tabular}{|l|l|l|} 
Показатели ЭМГ & Результаты временных показателей ЭМГ (в сек.) мышц: \\
\cline { 2 - 3 } Группы 1 & собственно жевательные & $p$ \\
\hline БЭА & $0,44 \pm 0,04$ & $p<0,05$ \\
\hline БЭП & $0,38 \pm 0,03$ & $p<0,05$ \\
\hline «К» & $1,25+0,07$ & $p<0,05$ \\
\hline ДЦ & $0,82+0,13$ & $p<0,05$ \\
\hline К-ВО ДЦ & $28,5+1,8$ & $p<0,05$ \\
\hline ППЖ & $23,4+1,60$ & $p<0,05$ \\
\hline
\end{tabular}

Эффективность ортодонтического лечения оценивали с помощью электромиографии. Использовали электромиограф «Медикор» (Венгрия), использовали при регистрации биопотенциалов собственно жевательных мышц, который осуществляет регистрацию биопотенциалов от 5 до 500 мкВ/мм. Регистрация частот осуществлялась в диапазоне 2-10000Гц. При выполнении ЭМГ собственно жевательных мышц интенсивность общей электрической активности, связана с силой её сокращения, в связи с чем результаты анализа данных, полученных при максимальном напряжении мышц в состоянии смыкания зубных рядов в центральной окклюзии позволяли оценивать силу сокращения с обеих сторон.

Биопотенциалы фиксировали во время жевательных движений на ЭМГ. Максимальную амплитуду при этом обозначали - «Ан». Сумма чередования биоэлектрической активности (БЭА) «всплесков» и прямых линий (биоэлектрического покоя) БЭП обозначали «динамический цикл» (ДЦ). Акт глотания завершал процесс жевания и характеризовался положением зубных рядов в центральной окклюзии. Акту глотания на ЭМГ соответствовал последний период БЭА, который был большей амплитуды и более продолжительный по времени.

При проведении анализа собственно жевательных мышц, количественных параметров состоял из показателей амплитудных (в мкВ) и временных в секундах. БЭА и БЭП сумма средней продолжительности - (ДЦ) время одного динамического цикла. Также учитывали время полного периода жевания (ППЖ). Коэффициентом «К» являлось отношение времени БЭА к БЭП. За весь период 
жевания включали и количество ДЦ во временной показатель.

В качестве пищевого стимулятора, одинакового для всех обследуемых, использовали двухдневный серый хлеб объёмом $1 \mathrm{~cm}^{3}$ и весом 1,5 г.

\section{Результаты исслеАования}

Результаты ЭМГ исследований (в мм) у лиц группы сравнения представлены в таблице 1.

Количественные показатели (мкВ/мм): Ан - наибольшая амплитуда биопотенциалов за весь период жевания; Ам - амплитуда биопотенциалов при максимальном напряжении мышц.

Полученные результата исследования показали, что у лиц группы сравнения наибольшая амплитуда собственно жевательных мышц во время жевания была меньше амплитуды биопотенциалов при максимальном сокращении собственно-жевательных мышц, в среднем на $50,5 \pm 12,3$ мкВ.

При проведении анализа сопоставили средние величины БЭА и БЭП. Временные параметры электромиограмм пациентов постоянными зубами с физиологической окклюзией представлены в таблице 2.

При исследовании пациентов первой группы результаты показали, что биопотенциалы собственно жевательных мышц наибольшая амплитуда, а при максимальном их напряжении амплитуда биопотенциалов также на электромиограммах была ниже в среднем на 42,5 $\pm 12,1$ мкВ, чем у группы сравнения.

Временные показатели собственно жевательных мышц пациентов 1 группы представлены в таблице 3.

Временные показатели ЭМГ пациентов первой группы коэффициент «К» был выше 1,25+0,07. Количество ДЦ увеличивалось и превышало 20. ППЖ на 9,2 с были выше, чем у лиц группы сравнения.

Временные показатели ЭМГ пациентов первой группы коэффициент «К» был выше 1,25+ 0,07. Количество ДЦ увеличивалось и превышало 20. ППЖ на 9,2 с были выше, чем у лиц группы сравнения.

После проведения лечения пациентов 1 группы несъёмными ортодонтическими аппаратами в связи со снижением амплитуды биопотенциалов коэффициент «К» был выше 1,25+ 0,07. Количество ДЦ увеличивалось до 20. У пациентов 1 группы ППЖ на 9,2 с были выше, чем у лиц группы сравнения.
На этапе завершения лечения пациентов первой группы коэффициент «К» стал $=0,87$. Количество ДЦ жевательных мышц уменьшилось до 18,1. ППЖ у пациентов первой группы стали сопоставимы с группой сравнения. Сократительная способность собственно жевательных мышц стала сопоставима с группой сравнения.

Таким образом, комплексное лечение пациентов 1 группы способствовало улучшению функциональных и эстетических показателей.

Электромиографические исследования пациентов второй группы показали, что амплитуды биопотенциалов были низкие, коэффициент «К» был выше - 1,32+ 0,09. Количество ДЦ собственно жевательных мышц превышало и увеличилось 24. ППЖ были выше у 2 группы, чем у лиц группы с которой проводили сравнение.

Пациентов второй группы после лечения коэффициент «К» стал $=0,88+0,05$. Количество ДЦ жевательных мышц уменьшилось до 17,3. ППЖ у пациентов второй группы стали сопоставимы с группой сравнения. Сократительная способность собственно жевательных мышц также стала сопоставимы с группой сравнения.

При проведении ЭМГ исследования пациентов третьей группы были снижены амплитуды биопотенциалов, коэффициент «К» был выше 1,36 + 0,08. Количество ДЦ увеличивалось и превышало 28. ППЖ у пациентов 3 группы был выше на 9,2 с выше, чем у лиц группы сравнения.

У пациентов третьей группы после проведенного лечения коэффициент «К» стал = 0,89+0,03. Количество ДЦ жевательных мышц уменьшилось до 18,2. ППЖ у пациентов третьей группы стали сопоставимы с группой сравнения. Сократительная способность собственно жевательных мышц стала сопоставима с группой сравнения.

В заключение следует отметить, что выбор и использование различных стратегий ортодонтического лечения невозможно осуществлять без получения представлений об изменениях, происходящих в зубочелюстной системе, а также в отсутствие данных об эффективности различных подходов к лечению пациентов со скученностью зубов. При планировании ортодонтического лечения данных пациентов целесообразно использование предложенного нами алгоритма, который предполагает выбор рационального персонализированного подхода. Мы надеемся, что результаты представленной работы внесут посильный вклад в углубление понимания процессов, лежащих в основе патогенеза рассматриваемой патологии, и позволят более эффективно осуществлять диагностику степени выраженности дефицита пространства в зубной дуге, планирование и лечение скученного положения зубов. 


\section{ЛИТЕРАТУРА}

1. Карпанова А.С., Арсенина 0.И., Грудянов А. И. и др. Совершенствование диагностики при планировании ортодонтического лечения // Стоматология.2018. - T. 97, № 6-2.- С. 28-31.

2. Нетцель Ф., Шультц К. Практическое руководство по ортодонтической диагностике. Анализ и таблицы для использования в практике / Пер. с англ.Львов: Гал-дент, 2006.- 175 с.

3. Панкратова Н.В., Слабковская А.Б. Методика определения размеров зубных рядов в зависимости от размеров нижних резцов// Ортодент- Инф0.1998. — № 1.- С. 6-8.

4. Слабковская А.Б., Панаиотов И.П. Мультидисциплинарное лечение в современной реставрационной стоматологии // 0ртодонтия.- $2014 .-$ № 2 (66).- С. 39-47.

5. Снагина Н. Г. Методы измерения зубных рядов и их практическое значение // Теория и практика в стоматологии. — 1969.— Вып. 15.— С. 284.

6. Шкарин В. В. Междисциплинарный подход в оказании стоматологической ортопедической помощи при дефектах зубных рядов // Современные проблемы здравоохранения и медицинской статистики. - 2019. — № 1. — С. 105-122.

7. Bansal A.V., Bansal A., Kulkarni V. K. et al. Multidisciplinary management of an unusual case of multiple developmental defects in lateral incisor followed by intrusive injury to primary incisors // Contemp. Clin. Dent.—2012.—Vol.3(4).—P. 510-513.

(с Климов Андрей Геннадьевич ( pstom4@zdrav.spb.ru ), Рожкова Мария Геннадьевна ( rozmaria2010@yandex.ru ),

Лепилин Александр Викторович ( lepilins@mail.ru ), Кондратюк Андрей Александрович ( kondratyuk.andrey@icloud.com ),

Фищев Сергей Борисович ( super.kant@yandex.ru ), Орлова Ирина Викторовна ( orisha@mail.ru ).

Журнал «Современная наука: актуальные проблемы теории и практики»

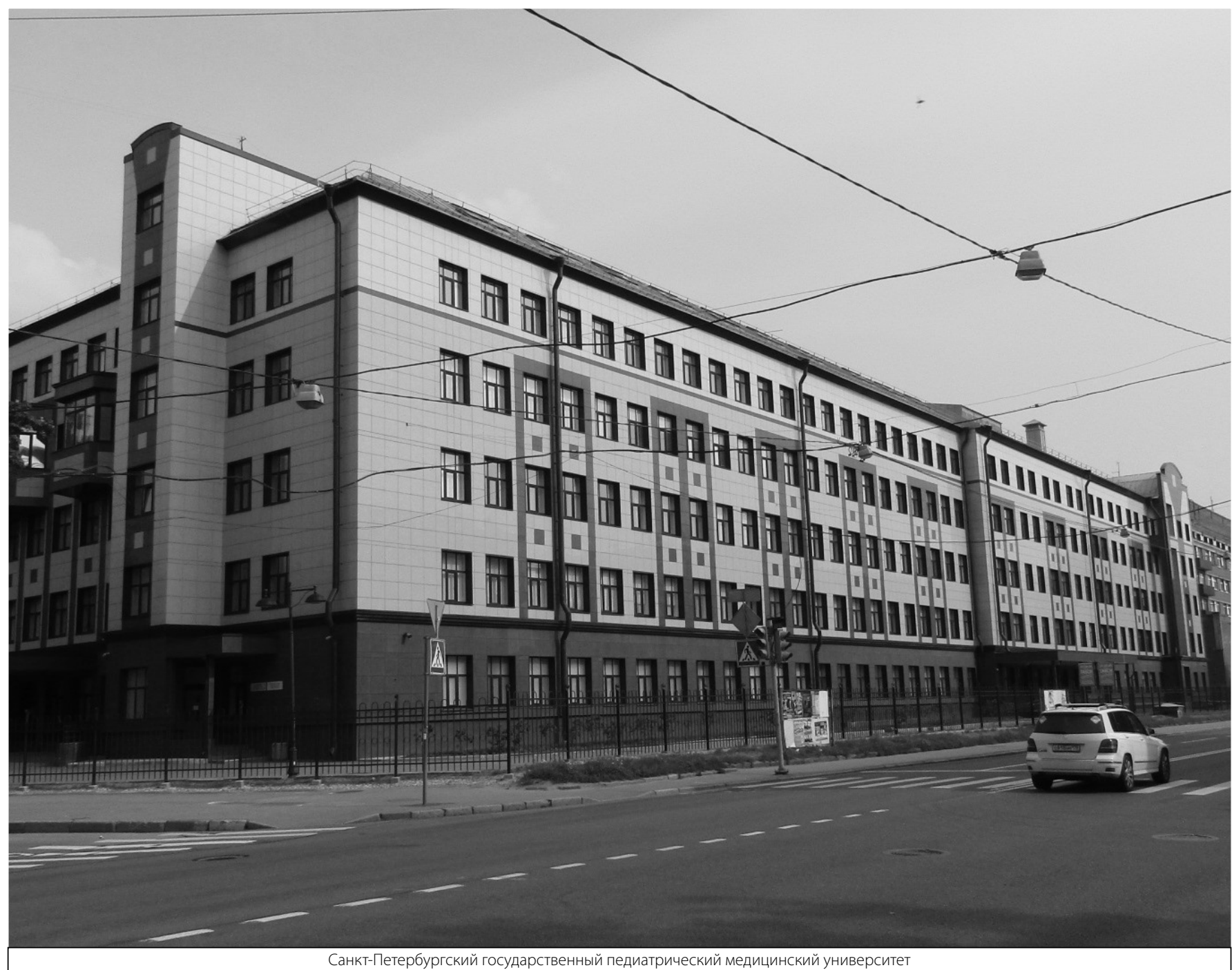

